\title{
EXPLORING STUDENTS' ATTITUDES TOWARDS ONLINE-BASED LEARNING SYSTEM IN THE NEW NORMAL: AN EXPLORATORY FACTOR ANALYSIS
}

\author{
Alliesa R. Acuña, \\ Flore Aubrey R. Aman, \\ Princess Dawn D. Apas, \\ Tomas Jr A. Diquito ${ }^{i}$ \\ University of Mindanao, \\ Digos College, \\ Digos City, \\ Philippines
}

\begin{abstract}
:
The implementation of online learning modality in the "New Normal Education" shifted the track of education institutions across the globe from conducting face-to-face classes to holding online-classes. The study presented in this paper aimed to explore students' attitude towards online-based learning system in the "New Normal" education. Specifically, it investigated the factor structure and the level of attitudes of 200 students towards online-based learning system. This study utilized a mixed method of research utilizing in-depth interview and a dimension reduction technique through Principal Component Analysis. Results revealed that, attitudes toward online-based learning system is multidimensional exploring eight dimensions namely: Engagement, Convenience, Satisfaction, Technology Acceptance, Adaptability, Interaction, SelfRegulation and Control. Moreover, the level of attitudes of students revealed a high level of convenience, technology acceptance, adaptability, interaction, assessment satisfaction, self-regulation and control and a moderate level of student engagement. Thus, the researchers recommend a training proposal for teachers as well as recalibrating the result of the study utilizing Confirmatory Factor Analysis.
\end{abstract}

Keywords: student's attitude, online-blended learning, new normal education

\section{Introduction}

With the outbreak of COVID-19 pandemic, many schools, colleges and universities across the globe have shifted to online learning to strictly follow health protocols. However, the implementation of this learning modality posed different risks, problems and challenges

i Correspondence: email tomasdiquito@umindanao.edu.ph 
to students and other educational stakeholders, especially in the higher education institutions (Bao, 2020). While this could be the case, future research should consider learners' perceptions and attitudes regarding online learning to discover the difficulties faced by students (Mailizar, Almanthari, Maulina \& Bruce, 2020).

Globally, most countries have temporarily closed their educational institutions which has affected more than 1.2 billion learners worldwide (UNESCO, 2020). With the adoption of online-based learning, most students get easily bored and show dissatisfaction due to several factors such as environmental influence (Wijaya, Zhou, Parnama \& Hermita, 2020) lack of stable internet connectivity (Chua, Sibbaluca, Miranda, Palmario, Moreno \& Solon, 2020) and financial crisis and mental pressure (Ramij \& Sultana, 2020). Students from countries like Indonesia (Wijaya et al., 2020), India (Gaur, Mudgal, Kaur \& Sharma, 2020) and Pakistan (Adnan \& Anwar 2020) experienced similar issues in dealing with online learning up-to-date. Hence, Basilaia \& Kvavadze (2020) proposed that the nature of online learning in consideration of students' attitude should be explored in future studies.

In the Philippines, the closure of schools has affected more than 28 million learners as revealed by the United Nations Educational, Scientific, and Cultural Organization (2020). With the increasing number of confirmed cases based on the Department of Health (2020) online tracker report, higher institutional education opted to utilize online learning system. However, some students have shown little to no interest learning in an online environment due to lack of resources and training. With this, colleges and universities have struggled with accommodating the abrupt change from face-to-face to online learning (Chua et al., 2020).

Locally, a study conducted at the University of Mindanao Digos College revealed that students have positive and negative experiences in their learning with regards to the asynchronous instruction (Diez et al., 2021). It is on the above context that the researchers would like to explore the attitudes of students when it comes to online learning in the new normal in the context of University of Mindanao Digos College. The findings may give insights to educational stakeholders about the dimensions of students' attitudes that influence their learning in an online environment. With this, existing policies can be assessed to address effective online learning in the new normal.

\section{Objectives}

This study aims to explore the attitude of students receiving online learning in the new normal. Specifically, it sought to answer the following objectives:

1) Determine the factor structure of student's attitudes towards online-based learning system in the new normal setting.

2) Determine the level of attitudes of students towards online-based learning system in the new normal. 


\section{Method}

This study utilizes a mixed method approach using descriptive qualitative and quantitative techniques. Mixed method is an approach to inquiry that combines or associates both qualitative and quantitative forms of research (Creswell, 2009). Specifically, this study utilizes exploratory design of research. This design is a two-phase approach that begins qualitatively, for exploring a phenomenon, followed by the quantitative data collection phase. Moreover, a descriptive research was also employed to obtain information through determining the nature of a situation as it exists at the time of the study.

This study was conducted at the University of Mindanao-Digos College, an institution located in the Southern part of the Philippines. In employing the data gathering procedure, a qualitative data collection was gathered first followed by the quantitative data. In selecting the participants of the qualitative study, the following inclusion criteria are strictly followed: (1) the participant must be officially enrolled in the institution in the SY 2020-2021; (2) that the participant is officially enrolled in the institution for at least one (1) semester; (3) has attended online classes in the institution; (4) willing to be interviewed, (5) willing to be the representative of the program being enrolled. After the rigorous process of selecting the participants, a total of 13 participants coming from different departments were selected. In-depth Interview using google meet was used in obtaining the qualitative data. In analyzing the qualitative data, Collaizi's (1978) method of analysis was used. Identified themes were taken and constructed as the questionnaires to be used in the quantitative phase. A total of 93 items were constructed and undergo reliability test to determine the factors needed in the study. These 93 items were given to 200 respondents of the study. The selection of the respondents was similar to the selection of participants in the qualitative phase, except that respondents only answer the questions using survey questionnaire via google forms.

After obtaining the data, the factorability of the items was examined prior to the extraction of the factors. Several tests were performed to assess the suitability of the respondent data for factor analysis. These tests include Kaiser-Meyer-Olkin (KMO) Measure of Sampling Adequacy and Bartlett's Test of Sphericity. The KMO index ranges from 0 to 1, with 0.50 considered suitable for factor analysis and the Bartlett's Test of Sphericity should be significant $(\mathrm{p}<.05)$ for factor analysis to be appropriate (Hair et al., 1995). Thus, based on the employment of these tests, the KMO measure appeared to be more than adequate with a sampling adequacy measure of 0.943 . To assess the internal reliability of the data set, Cronbach's alpha was also administered and the result revealed a ratio of 0.989 which is considered to be very high. Meanwhile, Bartlett's test of sphericity measures 21975.225 and Bartlett's coefficient $(p=0.000)$ is held significant. Given these overall findings, factor analysis was deemed suitable to be performed on the data. 


\section{Result and Discussion}

Table 1 shows the factor structure of attitudes of students towards online-based learning in the context of UMDC. Using principal component analysis, the underlying dimensions of the 93 attitude-related items were identified and the questions were grouped accordingly resulting to the retained eight-factor groups. The factor pattern from the eight retained factors was then transformed through varimax rotation. In assessing the practical significance of standardized factor loadings, Tapia (1996) indicated that for a sample size of exactly or more than 200 respondents, the factor loadings must be 0.4 or higher to consider the item significant. With this, item 42 (Some applications like Google Meet, Zoom, do not irritate me when it gets huge amount of data) was eliminated because its load falls below 0.4 and thus, failed to meet the minimum criteria.

The reliability of the eight-factor groups was further tested by means of Cronbach's coefficient of reliability. The alphas for the first four factors represent excellent internal consistency as supported by a very high Cronbach's alpha statistics that verifies a high reliability of the attitude groups.

Table 1: Factor Analysis of the Attitude Towards Online - Based Learning System in the New Normal

\begin{tabular}{|c|l|c|c|c|c|c|c|c|c|}
\hline Item & Item & \multicolumn{7}{|c|}{ Component } \\
\cline { 5 - 8 } & & $\mathbf{1}$ & $\mathbf{2}$ & $\mathbf{3}$ & $\mathbf{4}$ & $\mathbf{5}$ & $\mathbf{6}$ & $\mathbf{7}$ & $\mathbf{8}$ \\
\hline 39 & $\begin{array}{l}\text { The tasks that we are having right } \\
\text { now compared to the task that } \\
\text { we've had at face to face setting } \\
\text { are easier and not demanding. }\end{array}$ & .524 & & & & & & & \\
\hline 47 & $\begin{array}{l}\text { I don't feel any pressure brought } \\
\text { by other workloads. }\end{array}$ & .540 & & & & & & & \\
\hline 50 & $\begin{array}{l}\text { Feedback in this online set-up is } \\
\text { faster. }\end{array}$ & .507 & & & & & & & \\
\hline 58 & Online learning is fun. & .673 & & & & & & & \\
\hline 59 & I can still learn online if I just read. & .505 & & & & & & & \\
\hline 60 & $\begin{array}{l}\text { I haven't been bored learning } \\
\text { online. }\end{array}$ & .784 & & & & & & & \\
\hline 61 & $\begin{array}{l}\text { I am never irritated of this online } \\
\text { learning. }\end{array}$ & .760 & & & & & & & \\
\hline 62 & I can avoid cheating online. & .682 & & & & & & & \\
\hline 63 & $\begin{array}{l}\text { I don't search answers in the } \\
\text { Google. }\end{array}$ & .688 & & & & & & & \\
\hline 64 & $\begin{array}{l}\text { I have relaxed because of this } \\
\text { online class. }\end{array}$ & .776 & & & & & & & \\
\hline 65 & $\begin{array}{l}\text { I am not stressed in learning } \\
\text { online. }\end{array}$ & .779 & & & & & & & \\
\hline 67 & $\begin{array}{l}\text { I can really say that online } \\
\text { learning is conducive for learning. }\end{array}$ & .797 & & & & & \\
\hline
\end{tabular}




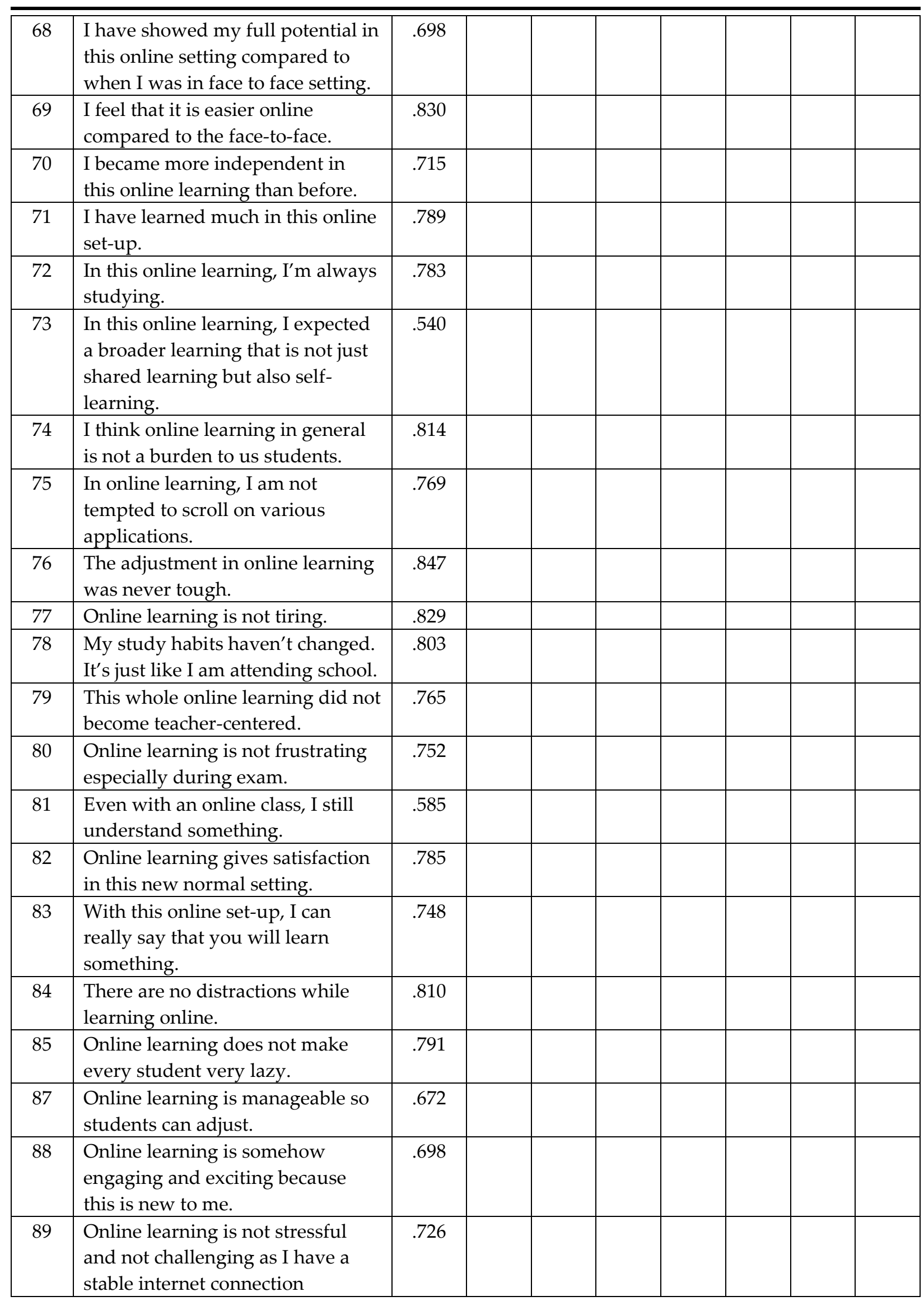




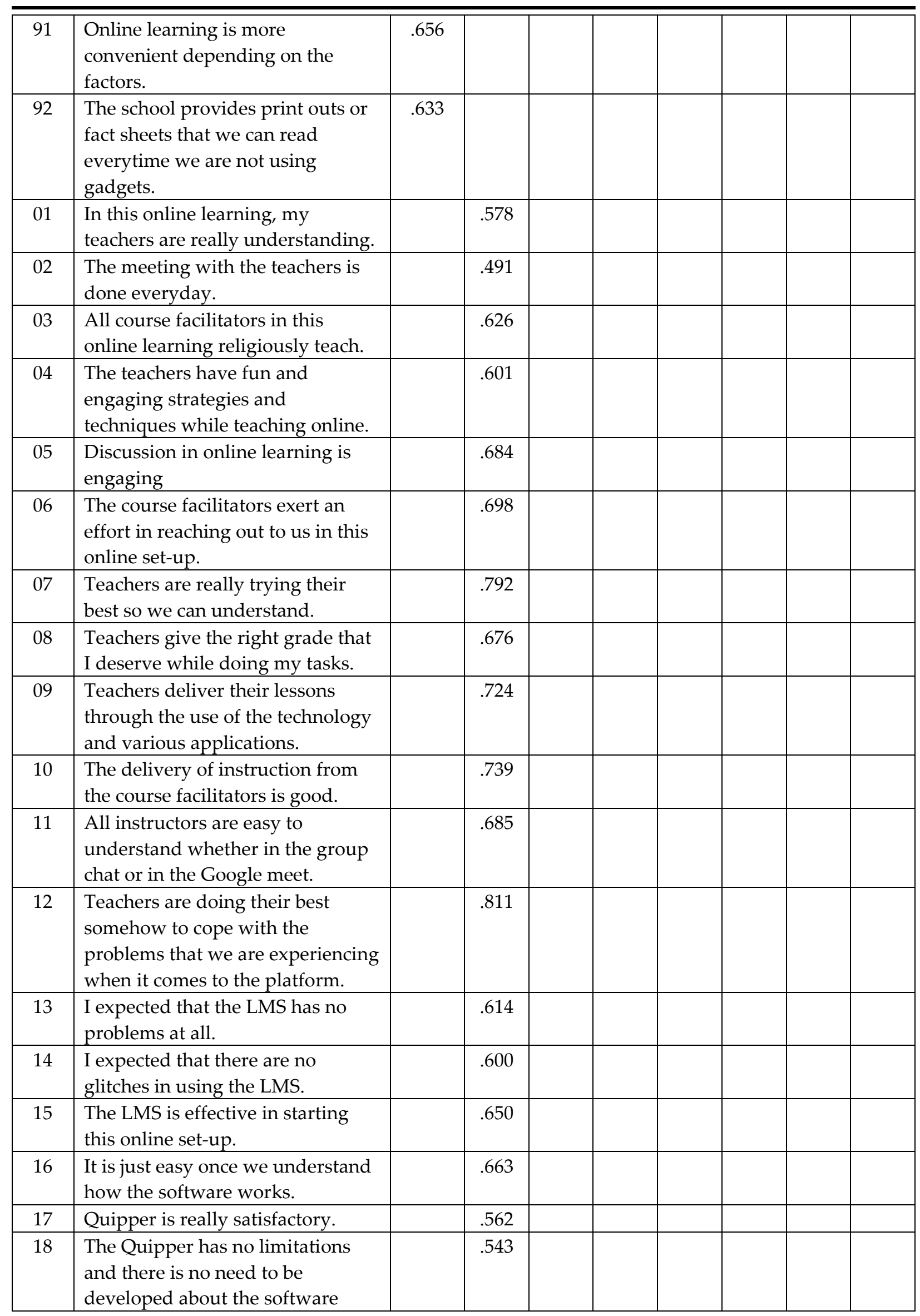




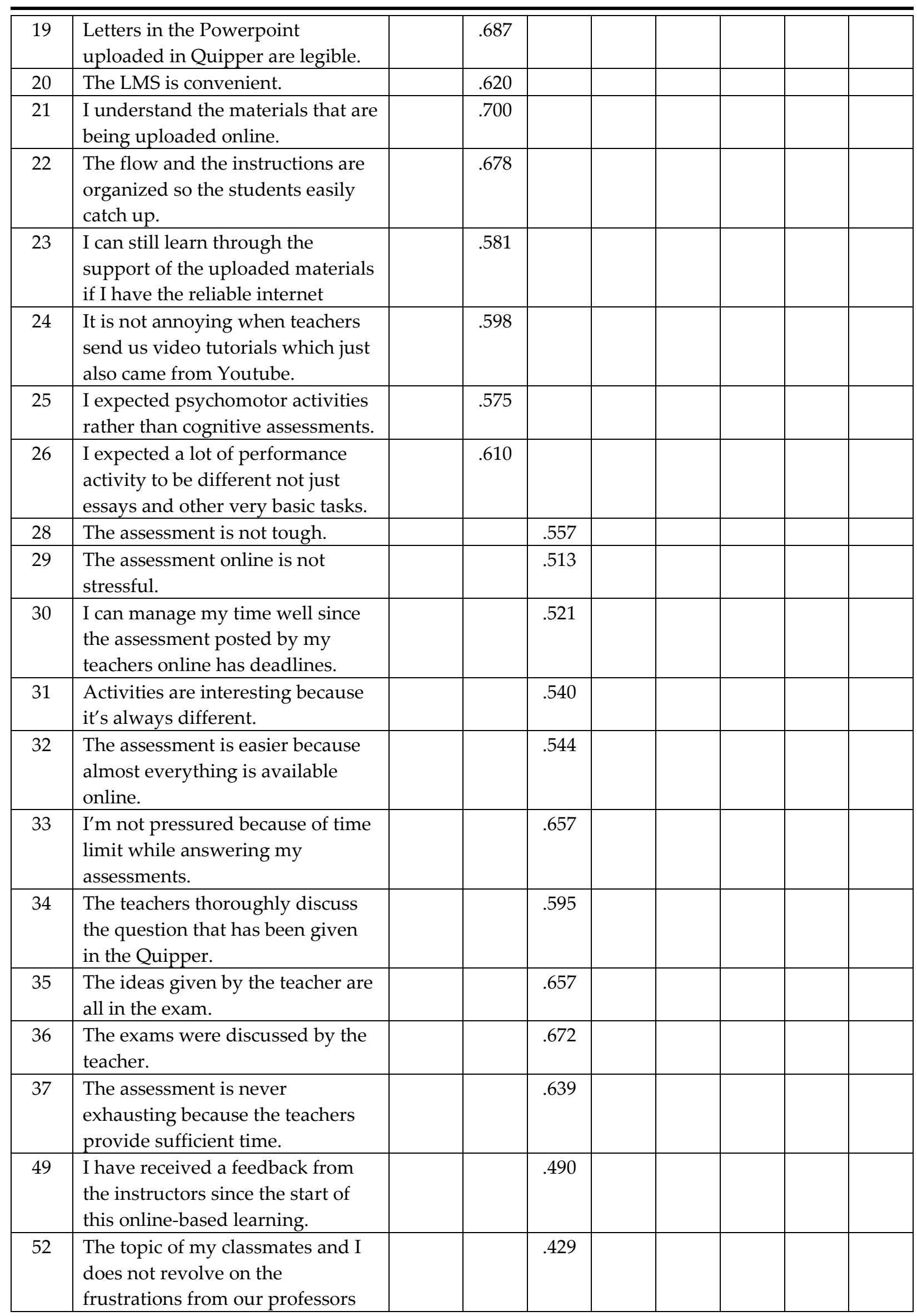




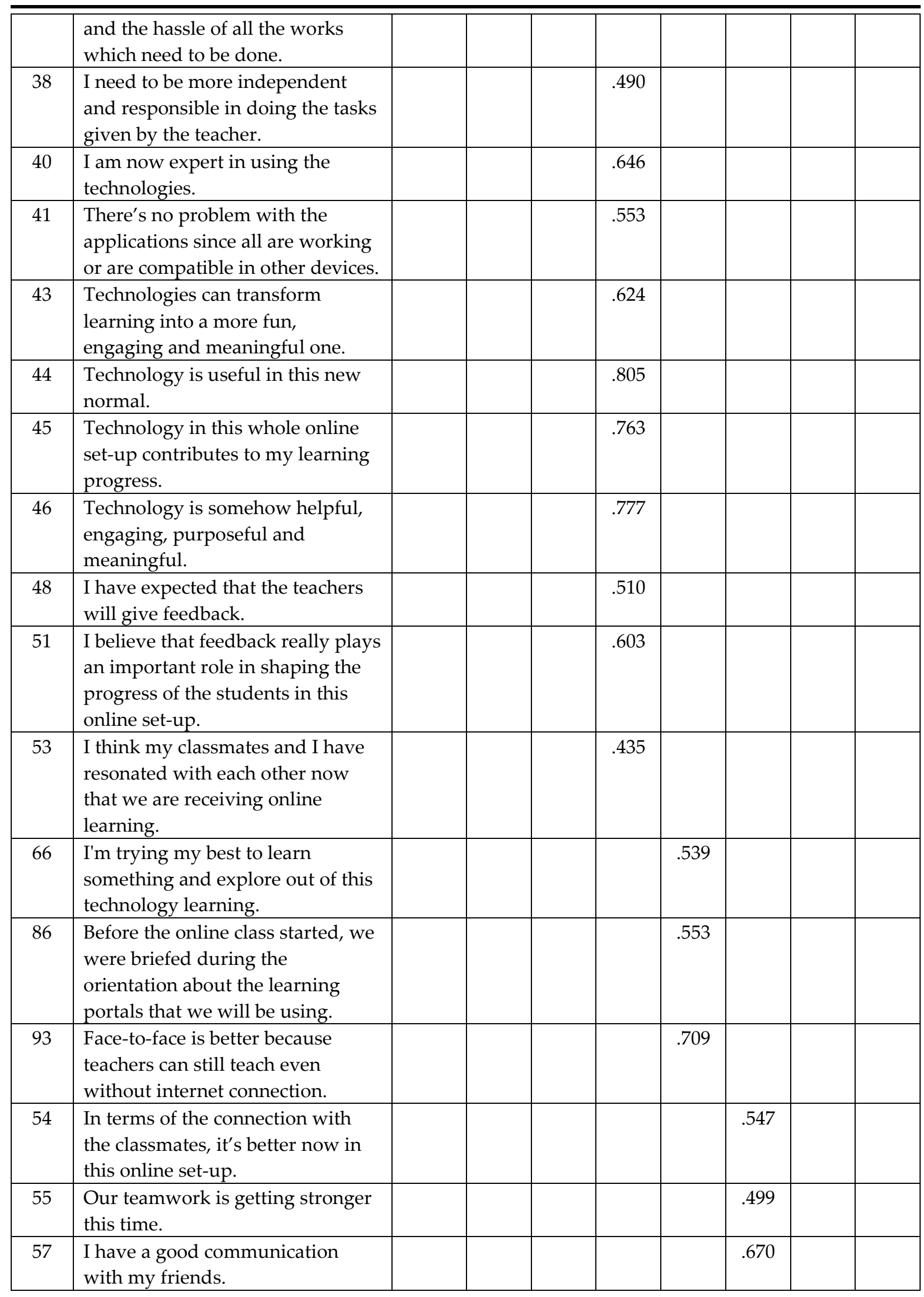




\begin{tabular}{|c|c|c|c|c|c|c|c|c|c|}
\hline 90 & $\begin{array}{l}\text { Online learning system allows } \\
\text { student to be independent in } \\
\text { exploring new ideas online. }\end{array}$ & & & & & & & .418 & \\
\hline 56 & $\begin{array}{l}\text { My classmates and I are not } \\
\text { copying because it's strict. }\end{array}$ & & & & & & & & .406 \\
\hline 27 & $\begin{array}{l}\text { The class assessment in the online } \\
\text { setting is strict and hard and is not } \\
\text { easy to cheat on. }\end{array}$ & & & & & & & & .510 \\
\hline \multicolumn{2}{|c|}{ Eigenvalue } & 46.702 & 7.305 & 3.594 & 3.147 & 1.890 & 1.644 & 1.519 & 1.197 \\
\hline \multicolumn{2}{|c|}{$\%$ Variance } & 50.22 & 7.86 & 3.86 & 3.38 & 2.03 & 1.77 & 1.63 & 1.29 \\
\hline Relic & ility by Cronbach $\alpha$ & 0.984 & 0.973 & 0.958 & 0.932 & 0.700 & 0.781 & - & 0.777 \\
\hline \multicolumn{10}{|c|}{ Cronbach $\alpha=0.989$} \\
\hline \multicolumn{10}{|c|}{$\mathrm{KMO}=0.943$} \\
\hline \multicolumn{10}{|c|}{ Bartlett's Test of Sphericity Chisquare $=.000$} \\
\hline
\end{tabular}

Meanwhile, the alphas for the next factors were considered to have good internal reliability showing values above 0.7 (Cronbach, 1951). It can be noted that Factor 7 did not indicate a reliability value since this factor only has 1 item and running a reliability test was deemed not possible. Furthermore, the eigenvalues and percentage of variance were also identified to guarantee the appropriateness of the items as indicators of the factors. The eigenvalues should be greater than one (eigenvalues $>1$ ) as those eigenvalues less than one accounts for less variability and thus, are not retained in the analysis (Girden, 2001).

Upon reviewing the items and examining the result, the first factor has indicated 35 items which consist of Item_39, Item_47, Item_50, Item_58, Item_59, Item_60, Item_61, Item_62, Item_63, Item_64, Item_65, Item_67, Item_68, Item_69, Item_70, Item_71, Item_72, Item_73, Item_74, Item_75, Item_76, Item_77, Item_78, Item_79, Item_80, Item_81, Item_82, Item_83, Item_84, Item_85, Item_87, Item_88, Item_89, Item_91 and Item_92 with a very high internal consistency of 0.984 and a high level of importance as it revealed $50.22 \%$ of the total variance and has an eigenvalue of 46.702 . This factor involves the general experiences of students towards online learning from attitudes, reflection, to management of their own learning. Thus, this dimension was named Engagement.

The second factor consisted of 26 items in the data set. It has a very high reliability of 0.973 and accounts for the total variance of $7.86 \%$ and an eigenvalue of 7.305 . Included in the items are Item_1, Item_2, Item_3, Item_4, Item_5, Item_6, Item_7, Item_8, Item_9, Item_10, Item_11，Item_12，Item_13，Item_14，Item_15，Item_16，Item_17，Item_18, Item_19, Item_20, Item_21, Item_22, Item_23, Item_24, Item_25 and Item_26. This factor discusses how students were able to perform tasks through the aid of various modes of instruction. Thus, this factor was named Convenience. Meanwhile, the third factor has a total variance of $3.86 \%$ and an eigenvalue of 3.594 . Upon the inspection of the items, 12 items were included which displayed a reliability of 0.954 . These items are Item_28, Item_29, Item_30, Item_31，Item_32，Item_33，Item_34，Item_35，Item_36，Item_37, Item_49 and Item_52. This factor involves the feelings and attitudes of students regarding 
their assessment stating that the assessment is not tough and stressful and emphasizing the role of feedback, among others. Thus, this dimension was named Satisfaction.

The fourth factor indicated 10 items which displayed a very high reliability of 0.932. These items include Item_38, Item_40, Item_41, Item_43, Item_44, Item_45, Item_46, Item_48, Item_51 and Item_53. The total variance accounts for $3.38 \%$ and has an eigenvalue of 3.147. This factor involves students' acknowledgement of the use of technology in this online learning. Thus, this dimension was named Technology Acceptance.

The fifth factor contained 3 items from the data set which consist of Item_66, Item_86 and Item_93 and has an internal reliability of 0.700 . It has $2.03 \%$ of the total variance and an eigenvalue of 1.890 . This factor involves adjusting to online learning by trying their best and learning how this modality will be accessed. Thus, this dimension was named Adaptability.

Going further, the sixth factor included 3 items in the data set. Items include Item_54, Item_55 and Item_57. It has a good reliability of 0.781 and accounts for the total variance of $1.77 \%$ and eigenvalue of 1.644 . This factor involves the connection and communication of students over their peers while learning online. Thus, this dimension was named Interaction.

The seventh factor with only Item_90 has a total variance of $1.63 \%$ and an eigenvalue of 1.519. This factor involves management of learning through independently exploring ideas online. Thus, this dimension was named Self-regulation.

Lastly, the eighth factor included 2 items in the data set particularly Item_56 and Item_27. It has a good reliability of 0.777 and has a total variance of $1.29 \%$ and an eigenvalue of 1.197. This factor involves control of students towards their actions in the learning environment particularly with regards to their assessment. Thus, this dimension was named Control.

Table 2: Level of Attitude towards Online - Based

Learning System in the New Normal by Factor

\begin{tabular}{|l|l|l|}
\hline Factor & Mean & SD \\
\hline Engagement & 3.14 & 0.90 \\
\hline Convenience & 3.73 & 0.70 \\
\hline Satisfaction & 3.45 & 0.84 \\
\hline Technology Acceptance & 3.80 & 0.69 \\
\hline Adaptability & 3.84 & 0.76 \\
\hline Interaction & 3.57 & 0.85 \\
\hline Self-regulation & 3.45 & 0.96 \\
\hline Control & 3.50 & 0.96 \\
\hline Overall & 3.56 & 0.83 \\
\hline
\end{tabular}

Based on the result of the conducted factor analysis, it can be revealed that the grouping of the attitude items into various factors is statistically justified. Table 2 shows the level of attitude of students towards online-based learning system in the new normal. Attitude of students explored eight factors namely: engagement, convenience, assessment 
satisfaction, technology acceptance, adaptability, interaction, self-regulation and control. The results showed that the level of attitude of students obtained an overall mean of 3.56 $(\mathrm{SD}=0.83)$ with a descriptive level "high". This indicates that the attitude of students towards online-based learning system in the new normal is satisfactory.

\section{A. Adaptability}

The adaptability dimension of attitude towards online-based learning system in the new normal obtained the highest mean score of $3.84(\mathrm{SD}=0.76)$ among all factors. As indicated in the data, the overall mean for the level of adaptability of students was verbally described as high. Based on the responses, the respondents perceived that they were briefed during implementation of the new modality of learning. They were oriented about the learning portals and they are trying their best to learn something and explore out of this technology learning.

\section{B. Technology Acceptance}

The technology acceptance dimension of attitude towards online-based learning system in the new normal obtained a mean of $3.80(\mathrm{SD}=0.69)$. As indicated in the data, the overall mean for the level of technology acceptance of students was high. Based on the result the respondents acknowledged the usefulness of technology-based learning.

\section{Convenience}

The convenience dimension of attitude towards online-based learning system in the new normal obtained a mean of $3.73(\mathrm{SD}=0.70)$. As indicated in the data, the overall mean for the level of satisfaction was high. The respondents displayed favorable responses among sub-items.

\section{Interaction}

The interaction dimension of attitude towards online-based learning system in the new normal obtained a mean of $3.57(\mathrm{SD}=0.85)$. As indicated in the data, the overall mean score for the level of interaction was high. Based on the result, the respondents have felt a strong bond among their peers. These include: have a good communication with friends; teamwork is getting stronger this time; and the connection with the classmates is better in online set-up.

\section{E. Control}

The control dimension of attitude towards online-based learning system in the new normal obtained a mean of $3.50(\mathrm{SD}=0.96)$. As indicated in the data, the overall mean for the level of control was high. Based on the result, respondents have showed good management over their own learning particularly with regards to dealing with their assessment. Respondents perceived that class assessment in the online setting is strict and hard and is not easy to cheat on and that they were not copying due to strict assessment implementation. 


\section{F. Satisfaction}

The satisfaction dimension of attitude towards online-based learning system in the new normal obtained a mean of $3.45(\mathrm{SD}=0.84)$. Respondents perceived that the assessment is easier because almost everything is available online, the exams were discussed by the teacher, the ideas given by the teacher are all in the exam, they have received a feedback from the instructors since the start of this online-based learning, the teachers thoroughly discuss the question that has been given in the Learning Management System (LMS), the assessment is not tough, they are not pressured because of time limit while answering assessments and the assessment online is not stressful.

\section{G. Self-regulation}

The self-regulation dimension of attitude towards online-based learning system in the new normal obtained a mean of 3.45, (SD=0.96). As indicated in the data, the overall mean for the level of self-regulation of students was high. Based on the result, respondents perceived that online learning allowed them to be independent in exploring new ideas online. It can be concluded that they were able to monitor their progress as they receive online education.

\section{H. Engagement}

The engagement dimension of attitude towards online-based learning system in the new normal obtained the lowest mean score of $3.14(\mathrm{SD}=0.90)$ among all factors. As indicated in the data, the overall mean for the level of engagement of students was moderate. Students have identified their experiences while receiving online learning. Interpretation of the result shows that attitude of students towards online learning is moderately satisfactory.

Based on the result of the study, the finding was found to be significantly below the threshold. Moreover, the level of students' engagement towards online-based learning system in the new normal is moderate obtaining the lowest mean score among all present factors.

\section{Conclusion}

Based on the findings of the study, the authors concluded that: The attitude of students towards online-based learning system in the new normal is multidimensional. The factor structure revealed eight factors, namely: Engagement, Convenience, Assessment Satisfaction, Technology Acceptance, Adaptability, Interaction, Competence and Control. Moreover, the level of attitude of students towards online-based learning system in the new normal in the context of the University of Mindanao Digos College is of a high level of convenience, technology acceptance, adaptability, interaction, satisfaction, selfregulation and control and a moderate level of engagement. 


\section{Recommendation}

The researchers recognized that the implications of their findings are only confined to the limits at which they interpret the results, and that these limitations must be addressed. Thus, in the light of foregoing findings and conclusions, the following recommendations are offered:

1) The study found out a moderate level of engagement among respondents of all academic departments. The researchers therefore recommend that administrators may evaluate and improve the effectiveness of existing policies and may implement necessary actions in addressing effective online learning in the new normal.

2) Training and workshop may be proposed to the faculty particularly on discussing interventions to improve their management, pedagogical and technical skills.

3) Based on the responses of the participants which revealed their educational needs, a focused-group discussion can be conducted to students to further discuss their learning struggles and difficulties while receiving online learning.

4) The researchers also recommend to further recalibrate the result of this study to address the limitations of this research. A confirmatory factor analysis can be done by future researchers to confirm the dimensionality of attitudes toward onlinebased learning system. Factor analysis can be utilized to validate the existing and present factors which served as dimensions of attitude towards online learning.

\section{Conflict of Interest Statement}

The authors declare no conflicts of interests.

\section{About the Authors}

Alliesa R. Acuña; Flore Aubrey R. Aman; Princess Dawn D. Apas are undergraduate students taking up Bachelor of Secondary Education major in Science at the University of Mindanao Digos College, Philippines under the supervision of Mr. Tomas Jr A. Diquito. Their research study has been presented in the international conference. Their interests include attitudes of students while learning in the new normal setting, strategies in teaching science, and game-based learning.

Tomas Jr. A. Diquito is a graduate of Master of Arts in Education major in Biology at the University of Southeastern Philippines. He is currently enrolled in PhD program at the same University. He is a Licensed Teacher in his country, teaching both professional and specialized courses. 


\section{References}

Adnan, M. \& Anwar K. (2020). Online Learning amid the COVID-19 pandemic: Students' Perspectives. Journal of Pedagogical research, 1, 45-51.

Bao W. (2020). COVID-19 and online teaching in higher Education: A case study of Peking University. Hum Behav \& Emerg Tech. 1(3). Retrieved from https://doi.org/10.1002/hbe2.191.

Basilaia, G., \& Kvavadze, D. (2020). Transition to online education in schools during a SARS-CoV-2 Coronavirus (COVID-19) pandemic in Georgia. Pedagogical Research, 5(4), em0060. https://doi.org/10.29333/pr/7937

Chua, E., Sibbaluca, B., Miranda, R., Palmario, G., Moreno, R. and T. Solon, J. P. (2020). The Status of The Implementation of the E-Learning Classroom in Selected Higher Education Institutions in Region Iv-A Amidst the Covid-19 Crisis. Journal of Critical Reviews. ISSN- 2394-5125 Vol 7, Issue 11, 2020.

Collaizi, P. (1978). Reflections and Research in Psychology: A Phenomenological Study of Learning. Dubuque, IA: Kendall/Hunt

Creswell, J. W. (2009). Research design: Qualitative, quantitative, and mixed methods approaches (3rd ed.). SAGE Publications, Inc.

Cronbach, L. J. (1951). Coefficient alpha and the internal structure of tests. Psychometrika, 16, 297-334. Retrieved from http://cda.psych.uiuc.edu/psychometrika citation classic summaries/cronbach citation classic alpha.pdf

Department of Health (DOH, 2020). Updates on Novel Coronavirus Disease. Retrieved from http://www.doh.gov.ph/2019-nCoV

Diez, J., Ebro, E., Dequito, R., \& Diquito, T. (2021). Uncovering learners' experiences to new normal education: implications of asynchronous instruction in GE 5: science, technology, and society course teaching. European Journal of Education Studies, 8(10). doi:http://dx.doi.org/10.46827/ejes.v8i10.393

Gaur, R., Mudgal, S. K., Kaur, S. and Sharma, R. (2020). Undergraduate nursing students' attitude towards online classes during lockdown period in India: imposed or interested? International Journal of Community Medicine and Public Health. Gaur $R$ et al. Int J Community Med Public Health. 2020 Sep;7(9):3371-3377 DOI: http://dx.doi.org/10.18203/2394-6040.ijcmph20203892. Retrieved from http://www.ijcmph.com

Girden, E. R. (2001). Evaluating research articles from start to finish. Thousand Oaks, Calif: Sage Publications. Retrieved from https://openlibrary.org/books/OL6777401M/Evaluating research articles from s tart to finish

Hair, J. F., Anderson, R. E., Tatham, R. L., \& Black, W. C. (1995). Multivariate data analysis. Englewood Cliffs, NJ Prentice-Hall. - References - Scientific Research Publishing 
Mailizar, Almanthari, A., Maulina, S., \& Bruce, S. (2020). Secondary school mathematics teachers' views on e-learning implementation barriers during the Covid-19 pandemic: The case of Indonesia. Eurasia Journal of Mathematics, Science and Technology Education, 16(7), em1860.

Ramij, M., \& Sultana, A. (2020). Preparedness of Online Classes in Developing Countries amid COVID-19 Outbreak: A Perspective from Bangladesh (SSRN scholarly paper ID 3638718). Social Science Research Network.

UNESCO. (2020). Education: From disruption to recovery. Retrieved from https://en.unesco.org/news/covid-19-learning-disruption-recovery-snapshotunescos-work-education-2020

Wijaya, T., Zhou, Y., Purnama, A. and Hermita, N. (2020). Indonesian students' learning attitude towards online learning during the coronavirus pandemic. Psychology, Evaluation, and Technology in Educational Research 3 (1), 2020, 17-25. 
Alliesa R. Acuña, Flore Aubrey R. Aman, Princess Dawn D. Apas, Tomas Jr A. Diquito

Creative Commons licensing terms

Author(s) will retain the copyright of their published articles agreeing that a Creative Commons Attribution 4.0 International License (CC BY 4.0) terms will be applied to their work. Under the terms of this license, no permission is required from the author(s) or publisher for members of the community to copy, distribute, transmit or adapt the article content, providing a proper, prominent and unambiguous attribution to the authors in a manner that makes clear that the materials are being reused under permission of a Creative Commons License. Views, opinions and conclusions expressed in this research article are views, opinions and conclusions of the author(s). Open Access Publishing Group and European Journal of Education Studies shall not be responsible or answerable for any loss, damage or liability caused in relation to/arising out of conflicts of interest, copyright violations and inappropriate or inaccurate use of any kind content related or integrated into the research work. All the published works are meeting the Open Access Publishing requirements and can be freely accessed, shared, modified, distributed and used in educational, commercial and non-commercial purposes under a Creative Commons Attribution 4.0 International License (CC BY 4.0). 